\title{
Shaping Lives, Molding an Industry: Symposium Honors the Life and Work of John T. Berry
}

\section{Lynne Robinson}

John T. Berry just didn't teach during his 60 -year career. He made dreams possible.

That's the assessment of Carolyn Meyers, who recently assumed the presidency of Jackson State University, Mississippi. "Dr. Berry was my first advisor at Georgia Tech," said Meyers. "He was so ahead of his time, supporting women and minorities in engineering long before the rest of the country caught up with him."

Prior to meeting Berry in the late 1970s, Meyers had been told that pursuing an advanced degree with three small children would not be possible. Berry, who was the Whirlpool Professor of Manufacturing Engineering at Georgia Tech at the time, thought differently. "He told me I was just fine, and encouraged me, worked with me, and supported me in not only my master's work, but also in pursuing my doctorate," said Meyers. "All through my studies at Georgia Tech, Dr. Berry opened doors of opportunity for me. He took the time and interest to expose me to the professional side of engineering by taking me to meetings, encouraging me to prepare and present papers, and guiding me to take his place as the Foundry Educational Foundation professor for Georgia Tech. He always pushed me and all of his students to dream big and to do more."

To celebrate Berry's influence on the lives and careers of Meyers and the myriad of other students he has mentored, as well as his seminal contributions to the casting industry, the TMS Light Metals Division has organized the Fourth International Shape Casting Symposium in his honor. The symposium will take place at the TMS 2011 Annual Meeting, February 27 to March 3 in San Diego. A highlight will be a paper presented by Berry-"The Estimable Value of 'Clever' Experiments."

Berry, now professor emeritus of mechanical engineering at Mississippi State University (Figure 1), noted that it was with a "mixture of delight and surprise" that he learned about his honorary symposium. "It confirmed my suspicion that people actually read and understood my publications," he joked.

Berry said metal casting was "in the blood," since his grandfather worked in a foundry and his father was a skilled patternmaker. Born and educated in the United Kingdom, earning both his undergraduate degree and Ph.D. in metallurgy from the University of Birmingham, Berry has experienced and

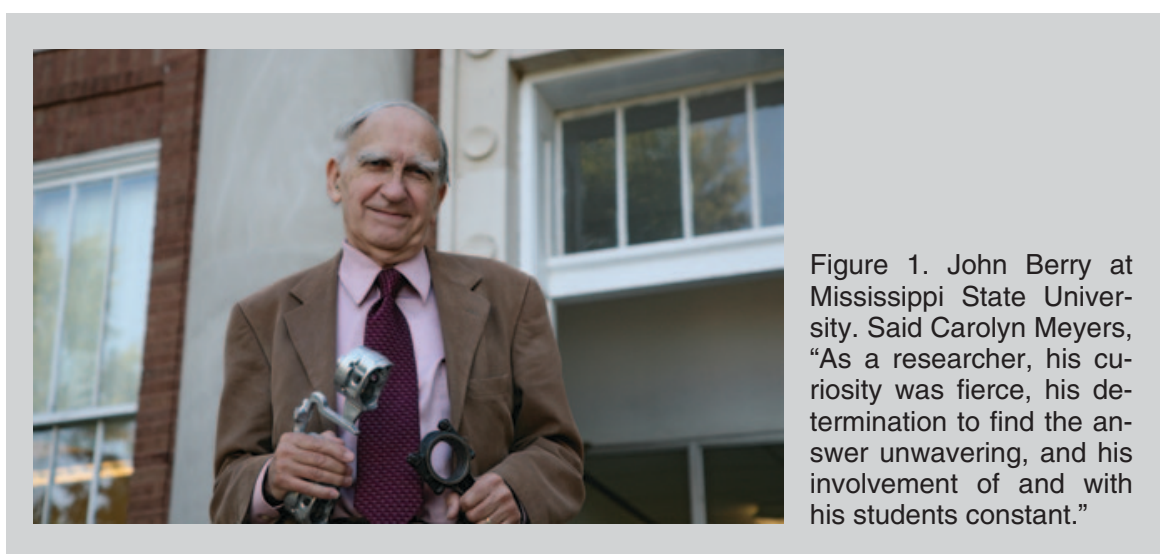

enriched nearly every aspect of metal casting, working in industry, research laboratories, and holding professorships at five different United States universities.

"He is encyclopedic with information regarding materials processing, materials design, and fracture and fatigue. I have used him as a sounding board for information and counsel on any ideas that I have had for development of plasticity, damage, and fatigue theories," said Mark F. Horstemeyer, Center for Advanced Vehicular Systems Chair (CAVS) and professor at Mississippi State. "I don't know of anyone who has as many years of experience with various metal alloys and their associated casting processes than Dr. Berry."

Horstemeyer credits Berry for encouraging him to help establish the CAVS and then "helping me adjust to the academic lifestyle" once he made the decision to accept the CAVS Chair at Mississippi State.

"When we look over our lives, we would like to think that we had an impact of some sort," Horstemeyer said. "And, perhaps the greatest impact one can have is transforming another person's life by your own life. John Berry has accomplished this with his many students and colleagues over his long history of research in materials."

"He gave me the chance to prepare myself for each of the positions I have held, and I treasure the solid footing and thoughtful insights that he provided me," echoed Meyers. "When I think of all the wonderful experiences I have had, I have to think of Dr. Berry."

Lynne Robinson is a news and feature writer for TMS. 